\title{
The Research of Deng Qisheng's Academic Ideology
}

\author{
${ }^{a}$ Y. PAN, ${ }^{b}$ J.L. YE \\ ${ }^{a}$ School of Architecture, South China University of Technology; State Key Laboratory of \\ Subtropical Building Science, South China University of Technology, Guangzhou, Guangdong, \\ China13380056897@163.com

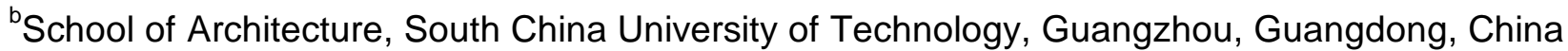 \\ 18680517657@163.com
}

KEYWORD: Deng Qisheng; Lingnan ancient architecture; academic ideology

ABSTRACT: Deng Qisheng, majoring in architectural history and theory, is a venerable professor of South China University of Technology. Professor Deng has been long engaged in the study of Chinese ancient architecture, whose academic directions cover many aspects of Chinese architecture history studies, such as the Lingnan architecture culture, the Chinese traditional gardens culture, the planning of scenic areas, the preservation of historical buildings and the reconstruction practice of Lingnan traditional cities. Professor Deng once put forward many valuable academic research ideas and conclusions, which have made great contributions to the development of architecture and urban construction in the Lingnan region. Based on the academic achievements of Professor Deng during 1979-2012, this paper attempts to sum up the academic ideologies and explores the inner context of his architectural creation concepts.

\section{BIOGRAPHY}

Deng Qisheng, born in Wuhua, Meizhou of Guangdong Province, has been staying for teaching after graduating from South China University of Technology in 1959, and finally became a professor and doctoral supervisor in 1992. Meanwhile, he was a first class national registered architect and worked as a visiting professor of Hong Kong University. He proposed lots of important academic points in the field of Chinese architecture history, and also pay attention to the research of Lingnan gardens and the practice of Chinese real estate theory. Devoting his life to the research and practice on architectural history and theory, Professor Deng published a total of 120 monographs and papers regarding the inheritance and development of classical Lingnan architecture. Moreover, he was committed to the conservation of ancient architecture and traditional cities, and participated in lots of reconstruction practice of traditional buildings and gardens. As a typical regional cultural scholar, he sticks to his own creative concept of architecture that the modern architecture design should be integrated with the ancient architecture theories. That is to say, making the past serve the present.

\section{THE MAIN ACADEMIC IDEOLOGY}

Professor Deng's academic achievements are mainly made after the cultural revolution. Through the study of Professor Deng's academic manuscripts and published papers, it can be found that the academic and practical results can be divided into three main aspects, including the research of the conservation and restoration of traditional building, the research of the traditional landscape gardening theory and the research of the urban renewal for Lingnan traditional cities.

Research on the conservation and restoration of traditional architecture

In the early period, Deng Qisheng was engaged in the research of architectural history and theory following professor Long Qingzhong, and paid more attention to the technology of disaster prevention and maintenance of ancient buildings. As the beginning of the academic career, the study of ancient architectural technology has laid a good foundation for a wide range of academic career.

Professor Deng put forward a viewpoint that ancient buildings not only have historical values but also practical functions, which play an import role in researching on the history of social development, the history of sciences and technologies, and the history of cultures and arts. In the article $R e$ - 
search on the Value and Utilization of Ancient Buildings published in 1980 (Deng, 1980), Professor Deng not only expounded the historical values and the realistic functions of ancient architecture, but also emphasized that the research of ancient architecture and the research of traditional culture should complement each other. The research of ancient architecture cover many aspects such as the influence of traditional culture, the impact of environment and the impact of various geographical location. Similarly, the ancient architecture plays an important role in the traditional culture. What's more, He pointed out that the research of ancient architecture has the function of inspiring the creation of regional architecture, and contributing to contemporary development of the Lingnan architectural creation (Deng, 1995b).

Professor Deng believed that the structure principle and the construction technology of the ancient architecture not only have certain scientific nature, but also the value of further research and summary. Making reasonable choices of materials and adopting proper protection measures is necessary to ensure successfully construction of the the ancient architectures. In the 1970s, he participated in the preparation of History of China's Ancient Architecture Technology (The Insititute for History of Natural Sciences, Chinese Academy of Sciences, 1985). After that he published a series of papers about the maintenance technology of ancient buildings. Inheriting Pro. Long's research on the disaster prevention technology of ancient buildings, he discussed the structure, failure reason and material technology of ancient buildings through field mapping and surveys.

For the restoration of ancient architecture, Professor Deng advocated the principle that repairing the old as the old. He also advocated that we should use scientific and economic means to protect historic buildings in accordance with the principle of no changing the original state. In some special cases, Professor Deng believed that we could reconstruct the ancient architecture in moderation. He proposed that the reconstruction should be as far as possible to restore the real history. Furthermore, the reconstruction should meet the needs of the historical environment and tourism. To this end, during reconstructing, we should not destroy the original cultural relics, but to use the original artifacts to build as far as possible. In the repairation of Zhuji Lane, Professor Deng adhere to keep the historical environment of the ancient village and to restore the original appearance on the premise of protecting the historical relics (Deng, 1995a).

\section{Research on the traditional landscape gardening theory}

Professor Deng has been long engaged in the traditional landscape gardening theory and architectural culture in the Lingnan region, so he is well versed in the feature of Lingnan architecture. Through the investigation of varies of Lingnan Gardens, he formed his own understanding of the characteristics of traditional landscape gardening. Based on the study of historical documents, he wrote Historical Garden Records (Deng, 1981) from the perspective of the development history of garden. He summed up the special management system of Chinese ancient afforestation which has a long history. From the beginning of the Qin Dynasty, there were some officials in charge of greening and planting flowers. In the article The Characteristics of Lingnan Ancient Culture published in 1982 (Deng, 1993c), he summarized the characteristics of Lingnan garden in the following three points: a long history, a high degree of popularity and a high level of horticulture. He concluded that the formation of Lingnan gardens landscape is based on regional climate environment first, local culture and aesthetic philosophy next.

Professor Deng pointed out that the aesthetic essence of Chinese traditional gardens is the circulation of space. And the way to get aesthetic feature is the application of the basic principle on landscaping, which is the use of artful following and borrowing (Deng, 1993a). He put forward that the conservation plannings of traditional gardens should draw lessons from the basic artifice and ecological priority on landscape based on formulating a large amount of conservation plannings of Guangdong traditional gardens (such as Sanbanggulsa , Keyuan Garden in Dongguan, and West

\section{Garden in Chaoyang ) (Gong\& Li, 2008).}

Based on the study of traditional landscape gardening theory, Professor Deng advocated that we should apply the landscape principle of traditional gardening theory to the construction of modern 
scenic areas (Deng, 1982). He explicated the natural spirit in the traditional landscape gardening, evaluated the value for the modern tourism planning, and discussed the creative spirit which the modern landscape architects should adhere to. Meanwhile, he emphasized the organic integration of the artificial environment and the natural environment, and advocated inheriting the cultural tradition and maintaining the ecological balance. For the landscape architecture design, he put forward following six principles:

1) Landscape architecture design should pay attention to the relationship between nature and architecture. It is important to make sure the position of the natural landscape, while the architecture is just a supporting role.

2) Landscape architecture should establish a amicable contact with natural environment to promote the integration of human and architecture in nature.

3) Landscape design concerns about the conception and space composition of the courtyard, and emphasizes forming a theme ornamental space through the effective organization of spatial relations between the architecture and landscape.

4) The changes of the visual angle should be given maximum attention in the organization of courtyard. Different perspectives can lead to different spatial feelings. the relationship between dynamic and static. Organizing the relationship of dynamic and static reasonably is the important way of performance space conception.

5) Landscape architecture pays more attention to dynamic and concerns about the arrangement of the tour route. While Lingnan curtilages pays attention to static and the use of artful following and borrowing. Following means that following the characteristics of local environment, while borrowing means the interactive relationship between the surrounding scenes.

6) The purpose of modern landscape architect design is to build a harmonious and comfortable living space for human beings through considering natural and social factors reasonably.

\section{Research on the urban renewal for Lingnan traditional cities.}

With the process of the reform and opening up and the growth of population and economy, there are many problems arised from the construction of the cities. In view of the problems of the urban renewal for famous historical and cultural cities, Professor Deng summed up the foreign advanced experience and his own understanding, and then put forward a lot of opinions on the urban renewal for traditional cities.

Professor Deng proposed that there are two modes in the expansion of urban city. One is to be iconoclastic, which means that tearing down the old city to build a new one. The other is the metabolism, which means that building a new town near the old city. The former mode will destroy the old buildings, the historical environment and the texture in the old city, which leads to the ecological deterioration and poor public security. However, the latter one refers to the principle that repairing the old as the old. That is to say, he is prefer to the way to restore the old appearance, and to partially keep and partially improve the old building, which follows the priceple of maintaining the old look of the old city.

Professor Deng stressed that the relationship between the old and the new is not opposite but harmonious. The development of the city should respect the history in stead of denying the previous civilization. In the article On the Development and Transformation of Famous Cities published in 1992, he pointed out that the renovation of old city is to solve the problem of messy and dilapidated. For the urban renewal for famous historical and cultural cities, he advocated respecting the original pattern of the city instead of renovation and demolition. Under this premise, it can be updated according to the metabolism principle.

Professor Deng has put forward many constructive opinions to the construction of Guangzhou by carrying out the concept of making the past serve the present. He published a series of articles such as The Urban Construction of Guangzhou Should Put More Effort to Make It Better (Deng, 1993a), as well as the article The Urban Construction of Guangzhou Should Pay More Attention to the Protection of Cultural Relics (Lin\& Deng, 1981) completed with Lin Keming. He stressed that we should protect historical architectures in Guangzhou in a comprehensive way, that is to line up the 
isolated historical architectures to form a region of protection. In order to achieve that goal, historical remarks and sites should be conserved legally. The duty of each related department must be implemented, and the fund should be sufficient. Secondly, the range of protection should be expand from isolated historical buildings to a region, such as buildings, blocks, villages and axis space. and establish necessary management and protection over that region. Lastly, the protection plan of each region can be treated as a whole which will enhance the effect of conservation. Moreover, Professor Deng also pays attention to ecological problems in urban construction as a concern for habitat and ecology and he advocates to build a landscape city (Deng, 2001).

In addition, Professor Deng also has certain academic achievements in other fields such as the architectural archaeology, the Lingnan architectural culture and the theory of real estate.

\section{CONCLUSION}

This paper summarized Professor Deng's academic ideology and analyzed the historical background of his theory system. It can be found that Professor Deng's academic research contains a wide range of directions. Most of his articles traced the cultural origins and historical value of traditional architecture, and focused on the analyses and suggestions on current events. Generally, his central idea is the valuable practical theories and suggestions of creation in that social environment based on the research of historical theories. The modern inheritance of traditional architecture means a general tendency to improving the character of Chinese architecture by learning from the valuable ideas of traditional Chinese architectural culture.

Professor Deng's research on Chinese ancient architecture in the current time is remarkable because he not only summarized the characteristics of cuture and technology of Lingnan traditional architecture, but also pioneered the theory of traditional landscape gardening. In addition, he put forward valuable suggestions for the residential environment and urban construction that are compatible with that circumstances. The ideology of his research is such valuable that it act as a guide for the present architectural research.

\section{REFERENCE}

Deng, Q.S. 1980. Research on the value and utilization of ancient buildings. Architecture and Construction (7): 22-25.

Deng, Q.S. 1981. Historical garden records. Journal of Guangdong Landscape Architecture (2): 15-24.

Deng, Q.S. 1982. The research on the innovation of landscape. Journal of Guangdong Landscape Architecture (1): $1-5$.

Deng, Q.S. 1983. The research of the traditional garden borrowing tactics. Journal of Guangdong Landscape Architecture (4).

Deng, Q.S. 1993a. The urban construction of Guangzhou should put more effort to make it better. New Architecture (2): 5-7.

Deng, Q.S. 1993b. The space characteristic of Sanbanggulsa. Journal of Chinese Landscape Architecture 9(01): 40-43.

Deng, Q.S. 1993c. The characteristics of Lingnan ancient culture. Architectural Journal (12): 16-18.

Deng, Q.S. 1995a. Exploration on the development mode of Nanxiong Zhuji Lane. Journal of Guangdong Landscape Architecture (2): 35-40.

Deng, Q.S. 1995b. The national spirit in Chinese ancient architecture. Traditional Chinese Architecture and Gardens (3): 20-34.

Deng, Q.S. 2001. Reconstruction of the city landscape in Guangzhou. South Architecture (1): 12-14.

Gong, X.Y \& Li, X.H. 2008. Introduction to Professor Deng Qisheng. South Architecture (5): 88-91.

Lin, K.M. \& Deng, Q.S. 1981. The urban construction of Guangzhou should pay more attention to the protection of cultural relics. South Architecture (1).

The Insititute for History of Natural Sciences, Chinese Academy of Sciences. 1985. The History of China's Ancient Architecture Technology. Beijing : Science Press. 